\title{
A Comparison of Estimated GFRs Based on Formulas of Serum Cystatin $C$ and Serum Creatinine
}

\author{
Nouraddin Mousavinasab, ${ }^{1}$ and Mojgan Jalalzadeh ${ }^{2,{ }^{*}}$ \\ ${ }^{1}$ Department of Biostatistics, Mazandaran University of Medical Sciences, Sari, IR Iran \\ ${ }^{2}$ Department of Nephrology, Loghman Hakim Hospital, Shahid Beheshti University of Medical Sciences, Tehran, IR Iran \\ "Corresponding author: Mojgan Jalalzadeh, Department of Nephrology, Loghman Hakim Hospital, Shahid Beheshti University of Medical Sciences, Tehran, IR Iran. Tel: \\ +98-2151025000, E-mail: jmojgan1341@gmail.com
}

Received 2017 February 22; Revised 2017 March 13; Accepted 2017 April 07.

\begin{abstract}
Background: Serum cystatin C has been identified as a marker for the estimation of glomerular filtration rate (GFR). Although this marker is more sensitive than creatinine, it is too expensive and not available in all laboratories. In this study, we compared cystatin C-based equations with creatinine-based formulas to select the most precise creatinine-based formula for estimating GFR in patients with chronic kidney disease (CKD).

Methods: 120 patients with CKD were enrolled in this cross-sectional study. The patients were divided into groups according to $\operatorname{BMI}(<25,25-29.9$, and $\geq 30)$ and age ( $\leq 40,41-60$, and $\geq 60)$. The patients' GFRs were estimated and analyzed by using three creatinine-based equations (modification of diet in renal disease (MDRD), abbreviated MDRD, and Cockcroft and Gault (C-G)) and five cystatin C-based equations (Filler, Le Bricon, Rule, Hoek, and Larsson).

Results: The mean age of patients was $56.4 \pm 16.4$ years. The mean of GFRs using C-G, MDRD, and abbreviated MDRD formulas were $36.2 \pm 14.3,32.6 \pm 11.4$, and $32.4 \pm 11.3 \mathrm{~mL} / \mathrm{min} / 1.73 \mathrm{~m}^{2}$, respectively. The mean of GFRs using Filler, Le Bricon, Larsson, Rule, and Hoek equations were $54.7 \pm 20.1,53.0 \pm 15.7,43.6 \pm 18.5,45.1 \pm 17.2$, and $46.2 \pm 16.2 \mathrm{~mL} / \mathrm{min} / 1.73 \mathrm{~m}^{2}$, respectively. The closest correlation was observed between GFRs generated by Abbreviated MDRD and cystatin C-based equations $\left(P<0.001, r: 0.4, R^{2}: 0.16\right)$. Differences in GFR estimation between cystatin C-based equations and C-G equation were lower at higher BMI levels (P: 0.004 - $0.01, \mathrm{~F}: 4.5$ - 6.7). Differences in GFR estimation between cystatin C-based equations and C-G as well as MDRD equations were greater in older patients (P: 0.01 - 0.04, F: 3.2 - 4.1).

Conclusions: GFRs estimated by Abbreviated MDRD equation are closer to GFRs estimated by cystatin C equations regardless of patients' BMI in CKD subjects.
\end{abstract}

Keywords: Glomerular Filtration Rate (GFR), Creatinine, Cystatin C, Chronic Kidney Disease (CKD), Body Mass Index (BMI)

\section{Background}

The best method to assess renal function is measuring the glomerular filtration rate (GFR) (1). Chronic kidney disease (CKD) patients are classified into stages 1-5 based on GFR. Inulin has been used as a gold standard indicator for measuring GFR (2). Other substances used as filtration markers include 125 Iothalamate, chromium51 ethylenediaminetetraacetic acid, and Iohexol (3). However, these substances are not often used because they are time-consuming, expensive, and difficult to process (4). Ideally, GFR should be determined with an accurate, inexpensive method. Estimation of GFR can be done using Modification of Diet in Renal Disease (MDRD), abbreviated MDRD, or Cockcroft and Gault (C-G) equations (5), which can present different results. Differences in results are due to the standardization of analytical techniques, the rate of production and tubular secretion of creatinine (6).

Furthermore, creatinine concentration is not only affected by GFR but also affected by other factors such as diet, muscle mass, gender, and age.

The best marker to estimate GFR should be a product that is produced continuously in the body and excreted by the kidney via free glomerular filtration without tubular absorption or secretion (7).

Cystatin $\mathrm{C}$ has been proposed as a new filtration marker to substitute creatinine, and it is very sensitive to changes in GFR (8). Cystatin C is a low molecular-weight basic protein $(13 \mathrm{kDa})$ that is produced at a constant rate by all nucleated cells of the body and freely filtered by the glomeruli of the kidney without tubular secretion and absorption (8).

Some investigators have suggested that serum cystatin $C$ has advantages over serum creatinine to estimate GFR as it is not affected by age, gender, muscle mass, drugs, and $\operatorname{diet}(9,10)$. However, some other investigators have questioned this idea (11). To determine GFR based on serum cystatin C, several equations such as Larsson, Hoek, Filler, Le Bricon, and Rule have been proposed (12-16). 
Studies have shown that BMI is related to the serum levels of cystatin C (17-19). The mechanism of this association is unclear, but experimental evidence suggests that adipocyte tissues secrete large amounts of cystatin C, which can lead to the increased levels of serum cystatin $C$ in obese individuals with high BMI (20). According to this assumption, estimated GFRs based on cystatin C formulas in obese cases may be different from those estimated by the gold standard. Whereas, in high BMI cases, it is expected that the result of GFR estimation by creatinine-based formulas be different from that of cystatin C-based equations.

In this study, we compared cystatin C-based equations with creatinine based formulas to identify the most precise formula to estimate GFR in Iranian population diagnosed with CKD. Also, the relation of these formulas results with patients BMI, age, and sex is presented.

\section{Methods}

In this cross-sectional study, we investigated 120 patients with $\mathrm{CKD}$, whose 3-month baseline GFR was less than $60 \mathrm{~mL} / \mathrm{min}$ per $1.73 \mathrm{~m}^{2}$.

Our exclusion criteria were pregnancy, liver cirrhosis, hypothyroidism, hyperthyroidism, or administration of any medication interfering with creatinine tubular secretion. Each subject gave his/her informed consent.

Non-fasting morning blood samples were taken and analyzed for serum creatinine, urea, and cystatin $C$. The Jaffe method was used to measure creatinine with a Boehringer Mannheim/Hitachi 747 analyzer. Serum cystatin C levels were determined with the Human cystatin C ELISA kit using Bio Vendor Laboratory Medicine, AS. The calibrated creatinine was used in all analyses involving the MDRD equations. GFR was estimated using the creatininebased MDRD, Abbreviated MDRD, and C-G equations (21) as well as the cystatin C-based Le Bricon (12), Filler (13), Hoek (14), Larsson (15), and Rule (16) equations per surface area of $1.73 \mathrm{~m}^{2}$, as shown in Table 1 .

For analysis, the patients were divided into three categories according to their BMI as: normal weight (BMI: 18.5 to $<25$ ), overweight (BMI: $25-30)$, and obese (BMI > 30). They were also divided into three groups according to their age as: under 40 years, 40 to 60 years, and more than 60 years.

\subsection{Statistical Analyses}

SPSS software (version 20.0) was used to analyze data. The normality of the distribution of variables was checked by one- sample Kolmogorov-Smirnov test. Pearson correlation coefficient was used to examine relations among quantitative variables. Linear regression models were used to determine relations among different methods of GFR assessment. Chi-square was used to compare qualitative variables in groups, two sample t-test to compare quantitative variables between two groups, and one-way analysis of variance (ANOVA) to compare quantitative variables between multiple groups. Student's t-test was used to evaluate each parameter in female and male groups. Spearman rank correlation, Mann Whitney U test, and Kruskal Wallis test were used for variables with non-normal distribution as appropriate non-parametric tests. A P value less than 0.05 was considered significant.

\section{Results}

Out of 120 patients, $45.8 \%$ (55) were female and 54.2\% were male (65). The mean age of patients was $56.4 \pm 16$ years. The patients' height ranged from 143 to $180 \mathrm{~cm}$ and the mean height was $163 \pm 8 \mathrm{~cm}$. The mean weight of patients was $68.2 \pm 11 \mathrm{~kg}$ ranging from 37 to $95 \mathrm{~kg}$. The mean BMI of the patients was $25.6 \pm 3 \mathrm{~kg} / \mathrm{m}^{2}$, mean creatinine was $2.2 \pm 0.6 \mathrm{mg} / \mathrm{dL}$, and mean cystatin $\mathrm{C}$ was $1.7 \pm 0.5$ $\mathrm{mg} / \mathrm{L}$.

The other characteristics of patients are shown in Table 2.

The mean values of estimated GFRs by three creatininebased formulas (C-G, MDRD, and abbreviated MDRD) and five cystatin C-based equations (Filler, Le Bricon, Larsson, Rule, and Hoek) are demonstrated in Table 3. Also, the frequencies of different CKD stages according to the GFR estimating formulas are shown in Table 3.

\subsection{Correlation Between Creatinine-Based and Cystatin C- Based Equations for GFR Estimation}

There was a strong significant relationship among GFR values estimated by three creatinine-based formulas ( $\mathrm{r}$ : 0.74 to 0.98 , P value $<0.0001$ ). Also, the correlation coefficient showed that there are significant correlations among all the five cystatin C-based GFRs estimating equations ( $\mathrm{r}$ : 0.99 to 1 , P value $<0.0001$ ).

In addition, based on the results, all of the creatininebased and cystatin C-based equations had a significant correlation for GFR estimation (P value $<0.001$ ), as demonstrated in Table 4.

The linear regression model of creatinine-based formulas and cystatin C-based equations for GFR estimation indicated that the most significant correlations were between abbreviated MDRD formula and Hoek and Le Bricon equations (r: 0.40), as shown in Figure 1 and 2.

As shown in Figure 1 and 2, the estimated GFRs by abbreviated MDRD are able to predict $16 \%$ of variances of the Hoek-estimated GFRs and Le Bricon-estimated GFRs (R square: 0.165). 
Table 1. Five Cystatin C-Based and Three Creatinine-Based Estimates of GFRs

\begin{tabular}{|c|c|}
\hline Equation & Formula, $\mathrm{mL} / \mathrm{min} / 1.73 \mathrm{~m}^{2}$ \\
\hline \multicolumn{2}{|l|}{ Cystatin C-based } \\
\hline Filler & $\log ($ GFR $)=1.962+(1.123 \times \log (1 /$ cystatin $C))$ \\
\hline Le Bricon & $\mathrm{GFR}=(78 \times(1 /$ cystatin $C))+4$ \\
\hline Hoek & GFR $=-4.32+(80.35 \times 1 /$ cystatin $C)$ \\
\hline Larsson & GFR $=77.24 \times$ cystatin $C^{-1.2623}$ \\
\hline Rule & GFR $=76.6 \times$ cystatin $C^{-1.16}$ \\
\hline \multicolumn{2}{|l|}{ Creatinine-based } \\
\hline MDRD & GFR $=170 \times$ creatinine $^{-0.999} \times$ age $^{-0.176} \times$ blood urea nitrogen ${ }^{-0.170} \times$ albumin $^{0.318} \times(0.762$ for women $) \times(1.180$ for African-Americans $)$ \\
\hline Abbreviated MDRD & $\mathrm{GFR}=186 \times$ creatinine $^{-1.154} \times$ age $^{-0.203} \times(0.742$ for women $) \times(1.212$ for African-Americans $)$ \\
\hline Cockcroft and Gault & GFR $=((140-$ age $) \times$ body weight $) /($ creatinine $\times 72) \times(0.85$ for women $)$ \\
\hline
\end{tabular}

Table 2. Demographic Characteristics of the Patients ${ }^{\mathrm{a}}$

\begin{tabular}{lc}
\hline Characteristics & Value \\
\hline Male & $55(45.8)$ \\
\hline Female & $65(54.2)$ \\
\hline Age, $\mathbf{y}$ & $56.41 \pm 16.4$ \\
\hline Hight, cm & $163.04 \pm 8.4$ \\
\hline Weight, Kg & $68.22 \pm 11.7$ \\
\hline BMI, kg/m ${ }^{2}$ & $25.65 \pm 3.9$ \\
\hline Serum creatinine, $\mathbf{m g} / \mathbf{d L}$ & $2.20 \pm 0.65$ \\
\hline Serum cystatin C, $\mathbf{~}$ g/L & $1.73 \pm 0.51$ \\
\hline Serum Albumin, $\mathbf{g} / \mathbf{d L}$ & $4.55 \pm 0.47$ \\
\hline BUN, $\mathbf{m g} / \mathbf{d L}$ & $41.76 \pm 18.3$ \\
\hline $\begin{array}{l}\text { a Values presented as number (percentage) for sex and mean } \pm \text { SD (range) for } \\
\text { other variables. }\end{array}$
\end{tabular}

The result of the study showed that there is a significant correlation between serum cystatin $\mathrm{C}$ and serum creatinine ( $r$ : 0.48 , P value $<0.001)$. On the other hand, there was not any significant correlation between BMI and creatinine ( $\mathrm{r}$ : -0.01, P value: 0.91 ,) and cystatin C ( $\mathrm{r}$ - -0.009 , P value: 0.92$)$.

3.2. Association Between Creatinine-Based and Cystatin CBased Equations for GFR Estimation and Their Relationship with BMI, Age, and Sex

The correlation between BMI and GFRs estimated by creatinine based-formulas is demonstrated in Table 5. Mean GFR estimated by C-G equation was higher in the cases with higher amount of BMI (P value $<0.001)$. However, changes in BMI did not show any significant relation-

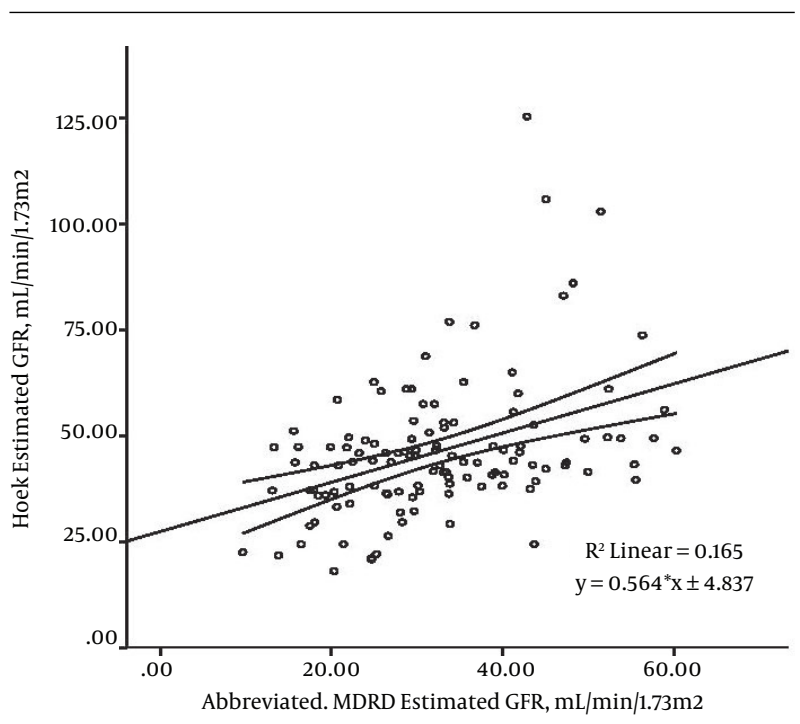

$\overline{\text { Figure 1. Correlation Between Abbreviated MDRD and Hoek Formulas for GFR Esti- }}$ mation

ship with the mean GFR estimated by other formulas ( $P$ value: 0.9 ).

The results showed that increases in age significantly reduce the mean GFR generated by C-G formula (P value < 0.0001 ). However, changes in age did not show any significant correlation with the mean GFR estimated by other formulas.

A relation was detected between GFRs from creatininebased formulas and gender, but such a relation was not found for GFRs from cystatin C-based equations. 
Table 3. Demographic Characteristics of the Patients (Estimated GFRs by Creatinine-Based and Cystatin C-Based Equations) ${ }^{\mathrm{a}}$

\begin{tabular}{|c|c|c|c|c|c|c|}
\hline Variables & Value & Stage 1 & Stage 2 & Stage 3 & Stage 4 & Stage 5 \\
\hline Cockcroft and Gault & $36.26 \pm 14.33$ & 0 & $7(5.8)$ & $72(60)$ & $36(30)$ & $5(4.2)$ \\
\hline Abbreviated MDRD & $32.44 \pm 11.38$ & 0 & $1(0.8)$ & $62(51.7)$ & $53(44.2)$ & $4(3.3)$ \\
\hline MDRD & $32.69 \pm 11.44$ & 0 & $2(1.7)$ & $63(52.5)$ & $52(43.3)$ & $3(2.5)$ \\
\hline Rule & $45.12 \pm 17.27$ & $3(2.5)$ & $12(10)$ & $91(75.8)$ & $14(11.7)$ & 0 \\
\hline Larsson & $43.69 \pm 18.52$ & $3(2.5)$ & $9(7.5)$ & $91(75.8)$ & $17(14.2)$ & 0 \\
\hline Hoek & $46.22 \pm 16.26$ & $3(2.5)$ & $13(10.8)$ & $90(75)$ & $14(11.7)$ & 0 \\
\hline Le Bricon & $53.06 \pm 15.78$ & $4(3.3)$ & $19(15.8)$ & $92(76.7)$ & $5(4.2)$ & 0 \\
\hline Filler & $54.78 \pm 20.18$ & $7(5.8)$ & $21(17.5)$ & $83(69.2)$ & $9(7.5)$ & 0 \\
\hline
\end{tabular}

${ }^{\mathrm{a}}$ Values presented as number (percentage) for sex and mean $\pm \mathrm{SD}$ (range) for other variables; GFRs expressed as $\mathrm{mL} / \mathrm{min} / 1.73 \mathrm{~m}{ }^{2}$.

Table 4. Correlation Among Creatinine-Based and Cystatin C-Based Equations for for GFR Estimation

\begin{tabular}{|c|c|c|c|c|c|c|}
\hline \multirow[t]{3}{*}{ Cystatin C-Based Equations } & \multicolumn{6}{|c|}{ Creatinine-Based Equations } \\
\hline & \multicolumn{2}{|c|}{ Cockcroft and Gault } & \multicolumn{2}{|c|}{ Abbreviated MDRD } & \multicolumn{2}{|c|}{ MDRD } \\
\hline & $\mathbf{r}$ & Pvalue & $\mathbf{r}$ & Pvalue & $\mathbf{r}$ & Pvalue \\
\hline Rule & 0.384 & $<0.001$ & 0.400 & $<0.001$ & 0.383 & $<0.001$ \\
\hline Larsson & 0.380 & $<0.001$ & 0.396 & $<0.001$ & 0.379 & $<0.001$ \\
\hline Hoek & 0.391 & $<0.001$ & 0.407 & $<0.001$ & 0.390 & $<0.001$ \\
\hline Le Bricon & 0.391 & $<0.001$ & 0.407 & $<0.001$ & 0.390 & $<0.001$ \\
\hline Filler & 0.386 & $<0.001$ & 0.402 & $<0.001$ & 0.375 & $<0.001$ \\
\hline
\end{tabular}

Table 5. Association Between Creatinine-Based and Cystatin C-Based Equations for for GFR Estimation and Their Relationship with BMI, Age, and Gender

\begin{tabular}{|c|c|c|c|c|c|c|c|c|c|c|c|}
\hline \multirow[t]{2}{*}{ Variables } & \multicolumn{4}{|c|}{ Body Mass Index } & \multicolumn{4}{|c|}{ Age, $y$} & \multicolumn{3}{|c|}{ Gender } \\
\hline & Normal Weight & Over weight & Obesity & P Value & $<40$ & $40-60$ & $>60$ & PValue & Male & Female & P Value \\
\hline Cockcroftand Gault & $30.5 \pm 11.1$ & $37.9 \pm 13.3$ & $47.1 \pm 18.0$ & $<0.001$ & $43.2 \pm 15.2$ & $41.9 \pm 14.9$ & $29.5 \pm 10.1$ & $<0.001$ & $31.9 \pm 11.7$ & $39.9 \pm 15.3$ & 0.003 \\
\hline Abbreviated MDRD & $33.3 \pm 12.2$ & $32.1 \pm 10.4$ & $33.5 \pm 12.2$ & 0.8 & $35.7 \pm 13.3$ & $32.4 \pm 11.7$ & $31.2 \pm 10.2$ & 0.6 & $26.6 \pm 8.8$ & $37.3 \pm 11.1$ & $<0.001$ \\
\hline MDRD & $32.4 \pm 12.2$ & $32.8 \pm 10.6$ & $33.0 \pm 11.9$ & 0.9 & $36.5 \pm 13.8$ & $32.1 \pm 11.7$ & $31.6 \pm 10.0$ & 0.5 & $27.2 \pm 9.1$ & $37.3 \pm 11.2$ & $<0.001$ \\
\hline Rule & $44.8 \pm 18.9$ & $45.1 \pm 13.7$ & $45.8 \pm 22.2$ & 0.9 & $44.0 \pm 9.6$ & $49.4 \pm 22.7$ & $42.1 \pm 13.6$ & 0.4 & $45.0 \pm 17.6$ & $45.2 \pm 17.1$ & 0.8 \\
\hline Larsson & $43.4 \pm 20.3$ & $43.6 \pm 14.6$ & $44.6 \pm 23.7$ & 0.9 & $42.4 .2 \pm 10.0$ & $48.3 \pm 24.7$ & $40.5 \pm 14.2$ & 0.4 & $43.6 \pm 19.0$ & $43.8 \pm 18.2$ & 0.8 \\
\hline Hoek & $45.8 \pm 17.8$ & $46.4 \pm 12.9$ & $46.7 \pm 20.9$ & 0.9 & $45.4 \pm 9.3$ & $50.2 \pm 21.0$ & $43.4 \pm 13.3$ & 0.4 & $46.1 \pm 16.4$ & $46.3 \pm 16.2$ & 0.8 \\
\hline Le Bricon & $52.6 \pm 17.3$ & $53.2 \pm 12.5$ & $53.7 \pm 20.3$ & 0.9 & $52.3 \pm 9.1$ & $56.9 \pm 20.4$ & $50.3 \pm 12.9$ & 0.4 & $52.9 \pm 15.9$ & $53.1 \pm 15.7$ & 0.8 \\
\hline Filler & $54.3 \pm 22.1$ & $54.8 \pm 16.0$ & $55.6 \pm 25.9$ & 0.9 & $53.6 \pm 11.3$ & $59.7 \pm 26.5$ & $51.2 \pm 16.0$ & 0.4 & $54.6 \pm 20.5$ & $54.8 \pm 19.9$ & 0.8 \\
\hline
\end{tabular}

3.3. The Prevalence of Stages 3-4 CKD by Using Creatinine-Based and Cystatin C-Based Formulas, and Their Relation with BMI, Age, and Sex

As presented in Table 6, the prevalence of stages 3-4 CKD is significantly lower in patients with higher BMI than patients with lower BMI (P value: 0.005) by using C-G formula, while no appreciable difference was seen between BMI groups using other formulas. In addition, the prevalence of stages 3 - 4 CKD, estimated by C-G and MDRD formulas, was affected significantly by age (P value: 0.03 and
0.008 , respectively). Also, there was no significant sex difference in the prevalence of stages 3 - 4 CKD.

3.4. Difference Between Creatinine-Based and Cystatin C-Based Formulas for GFR Estimation and Their Correlation with BMI, Age, and Sex

The differences between GFRs estimated by cystatin Cbased equations and those estimated by $\mathrm{C}-\mathrm{G}$ equation are lower at higher BMI levels (P value: 0.004 - 0.01), as shown in Table 7. 
Table 6. The Prevalence of Stages 3 - 4 CKD by Using Creatinine-Based and Cystatin C-Based Formulas, and Their Relation with BMI , Age, and Sex ${ }^{\mathrm{a}}$

\begin{tabular}{|c|c|c|c|c|c|c|c|c|c|c|c|}
\hline \multirow[t]{2}{*}{ Variables } & \multicolumn{4}{|c|}{ Body Mass Index, $\mathrm{kg} / \mathrm{m}^{2}$} & \multicolumn{4}{|c|}{ Age, $y$} & \multicolumn{3}{|c|}{ Sex } \\
\hline & Normal Weight $(18.5$ - 24.9) & Over weight $(25.0$ - 29.9) & Obesity $(\geq 30.0)$ & Pvalue & $<\mathbf{4 0}$ & $40-60$ & $>60$ & Pvalue & Female & Male & Pvalue \\
\hline No. & 50 & 52 & 18 & & 21 & 44 & 55 & & 55 & 65 & \\
\hline Abbreviated MDRD & $49(98)$ & $52(100)$ & $18(100)$ & 0.49 & $20(95.2)$ & $44(100)$ & $55(100)$ & 0.093 & $55(100)$ & $64(98.5)$ & 1.0 \\
\hline MDRD & $48(96)$ & $52(100)$ & $18(100)$ & 0.24 & $19(90.5)$ & $44(100)$ & $55(100)$ & 0.008 & $55(100)$ & $63(96.9)$ & 1.0 \\
\hline Rule & $44(88)$ & $45(86.5)$ & $16(88.9)$ & 0.95 & $20(95.2)$ & $36(81.8)$ & $49(89.1)$ & 0.27 & $50(90.9)$ & $55(84.6)$ & 0.41 \\
\hline Larsson & $45(90)$ & $47(90.4)$ & $16(88.9)$ & 0.98 & $20(95.2)$ & $37(84.1)$ & $51(92.7)$ & 0.24 & $50(90.9)$ & $58(89.2)$ & 0.49 \\
\hline Hoek & $43(86)$ & $45(86.5)$ & $16(88.9)$ & 0.95 & $19(90.5)$ & $36(81.8)$ & $49(89.1)$ & 0.48 & $49(89.1)$ & $55(84.6)$ & 0.83 \\
\hline Le Bricon & $39(78)$ & $44(84.6)$ & $14(77.8)$ & 0.65 & $16(76.2)$ & $33(75)$ & $48(87.3)$ & 0.25 & $46(83.6)$ & $51(78.5)$ & 0.49 \\
\hline Filler & $39(78)$ & $41(78.8)$ & $12(66.7)$ & 0.55 & $16(76.2)$ & $31(70.5)$ & $45(81.8)$ & 0.41 & $43(78.2)$ & $49(75.4)$ & 0.83 \\
\hline
\end{tabular}

${ }^{\mathrm{a}}$ Values are expressed as No. (\%)

Table 7. Difference Between Creatinine-Based and Cystatin C-Based Formulas for GFR Estimation and Their Correlation with BMI, Age, and sex

\begin{tabular}{|c|c|c|c|c|c|c|c|c|c|c|c|}
\hline \multirow{2}{*}{$\begin{array}{l}\text { Variables } \\
\text { Differences between cystatin-based } \\
\text { and creatinine-based equations }\end{array}$} & \multicolumn{4}{|c|}{ Body Mass Index, $\mathrm{kg} / \mathrm{m}^{2}$} & \multicolumn{4}{|c|}{ AGE, $y$} & \multicolumn{3}{|c|}{ Sex } \\
\hline & Normal Weight (18.5 - 24.9) & Over weight $(25.0-29.9)$ & Obesity ( $\geq$ 30.0) & PValue & $<40$ & $40-60$ & $>60$ & PValue & Female & Male & PValue \\
\hline Rule-Cockcroft-Gault & 14.20 & 7.23 & -1.20 & 0.004 & 0.79 & 8.09 & 12.58 & 0.031 & 13.11 & 5.3 & 0.015 \\
\hline Larsson-Cockcroft-Gault & 12.8 & 5.70 & -2.24 & 0.007 & 0.86 & 7.01 & 10.94 & 0.045 & 11.6 & 3.8 & 0.021 \\
\hline Hoek-Cockcroft-Gault & 22.09 & 15.30 & 6.47 & 0.002 & 9.02 & 15.58 & 20.76 & 0.018 & 21.06 & 13.2 & 0.01 \\
\hline Le Bricon-Cockcroft-Gault & 22.09 & 15.30 & 6.47 & 0.002 & 9.02 & 15.58 & 20.76 & 0.018 & 21.06 & 13.2 & 0.01 \\
\hline Rule-abbreviated MDRD & 12.44 & 13.02 & 12.32 & 0.98 & 8.31 & 17.02 & 10.87 & 0.073 & 18.3 & 7.8 & $<0.001$ \\
\hline Larsson-abbreviated MDRD & 11.04 & 11.49 & 11.08 & 0.99 & 6.65 & 15.95 & 9.23 & 0.068 & 16.9 & 6.4 & 0.001 \\
\hline Hoek-abbreviated MDRD & 13.48 & 14.26 & 13.17 & 0.95 & 9.67 & 17.79 & 12.12 & 0.082 & 19.4 & 8.9 & $<0.001$ \\
\hline Le Bricon-abbreviated MDRD & 20.33 & 21.10 & 20.00 & 0.95 & 16.54 & 24.52 & 19.05 & 0.083 & 26.3 & 15.8 & $<0.001$ \\
\hline Filler-abbreviated MDRD & 22.03 & 22.73 & 22.06 & 0.98 & 17.85 & 27.38 & 20.02 & 0.073 & 28.0 & 17.5 & 0.002 \\
\hline Rule-MDRD & 12.38 & 12.33 & 12.83 & 0.99 & 7.46 & 17.28 & 10.44 & 0.40 & 17.7 & 7.9 & 0.001 \\
\hline Hoek-MDRD & 13.41 & 13.57 & 13.68 & 0.99 & 8.83 & 18.05 & 11.69 & 0.044 & 18.9 & 8.9 & $<0.001$ \\
\hline Le Bricon-MDRD & 20.27 & 20.41 & 20.50 & 0.99 & 15.69 & 24.77 & 18.62 & 0.044 & 25.7 & 15.8 & $<0.001$ \\
\hline Filler-MDRD & 21.96 & 22.04 & 22.56 & 0.99 & 17.00 & 27.64 & 19.59 & 0.043 & 27.4 & 17.5 & 0.004 \\
\hline
\end{tabular}

The differences between GFRs estimated by cystatin Cbased equations and those estimated by C-G and MDRD equations were greater in older patients ( $\mathrm{P}$ value: 0.01 $0.04)$.

The differences between GFRs estimated by cystatin Cbased equations and creatinine-based equations were significantly different between males and females ( $P$ value: $0.15-0.001$ )

\section{Discussion}

Chronic kidney disease is an important public health problem. Estimation of GFR is essential for the evaluation of kidney function in CKD patients. The current kidney disease outcomes quality initiative (K/DOQI) guidelines classify CKD into five stages based on GFR estimations (10).
There is evidence showing that using creatinine concentration as an ideal marker for GFR estimation is accompanied by problems (22).

Studies have reported that cystatin $C$ is less affected by age, gender, and muscle mass when compared to serum creatinine (23) and it is not affected also by dietary protein intake, inflammation, fever, and agents such as proteins and bilirubin (24).

Our aim in this study was to compare cystatin C-based equations with creatinine based-formulas for estimation of GFRs.

Many studied have suggested that cystatin C concentration is a better indicator to estimate GFR than serum creatinine concentration $(9,10,25-30)$, especially in patients with spinal injury, liver cirrhosis, cystic fibrosis, diabetes, and old age (31). While, other investigators have reported 


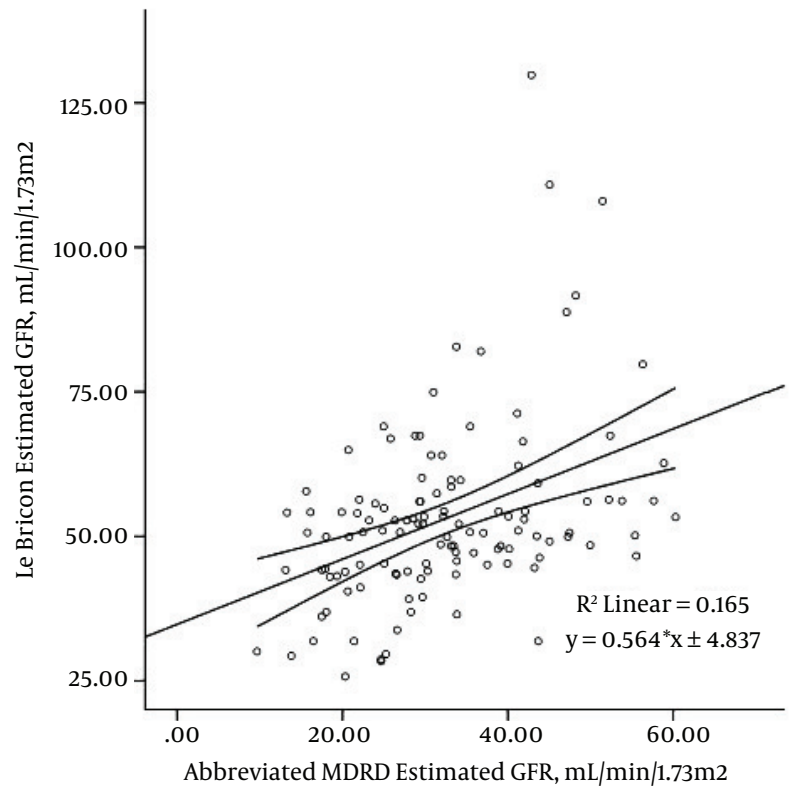

Figure 2. Correlation between Abbreviated MDRD and Le Bricon formulas for GFR estimation

that these two substances are equally accurate (14, 32-35).

Also, some researchers believe that many factors such as male sex, weight, height, cigarette smoking, higher serum $\mathrm{C}$ reactive protein levels, steroid therapy, and rheumatoid arthritis can increase the serum level of cystatin C. Thus, this substance may be less accurate to evaluate kidney function (35-38).

In this study, we calculated the GFRs of 120 patients with CKD based on creatinine and cystatin $C$ equations. The results indicated that there was a significant correlation between all creatinine-based estimated GFRs and cystatin C-based estimated GFRs (P value $<0.001$ ), and abbreviated MDRD-estimated GFRs were comparable with those of Hoek and Le Bricon equations in CKD subjects (P value < 0.001, r: 0.4, R2: 0.16).

In general, only the mean estimated GFR resulted from C-G formula was under the influence of BMI (P value < 0.001), because it was higher in individuals with higher BMI. Increasing age significantly reduced the mean estimated GFR (Pvalue $<0.0001)$. This result was expected due to the influence of age and weight on C-G formula. But, we do not have any explanation why BMI and age were not effective in other creatinine-based equations (Table 5).

In addition, a relationship was verified between GFRs estimated by creatinine-based formulas and gender, but such a relation was not found in GFRs from cystatin Cbased equations. Since the factors of weight, age, and gen- der are not considered in the cystatin C-based formulas, this result is not surprising.

On the other hand, since the number of patients on stages 2 and 5 CKD was low, we evaluated the effect of BMI, age, and sex on the prevalence of stages 3 - 4 CKD. The prevalence of stages 3 - 4 CKD, determined by C-G and MDRD formulas, was affected significantly by age (P value: 0.03 and 0.008 , respectively).

Also, BMI had an influence on the prevalence of stages 3 - 4 CKD in creatinine-based formulas although it was not statistically significant. The effect of BMI was statistically significant only when C-G formula was used (P value: 0.005). Patients with higher BMI had lower frequency in stages 3 - 4 CKD.

Also, there were no significant sex differences in the prevalence of stages 3 - 4 CKD patients ( $P$ value $>0.05$ ) by using creatinine-based formulas.

Differences in estimated GFRs between cystatin Cbased equations and C-G and MDRD equations were greater in older patients (P value: 0.01 - 0.04, F: 3.2 - 4.1).

In terms of differences between GFRs estimated by cystatin C-based equations and GFRs estimated by creatininebased formulas, they were lower at higher BMI levels when C-G equation was used (P value: $0.004-0.01$ ), and they were greater in older patients when C-G and MDRD equations were used (P value: 0.01 - 0.04). The differences were also significant between males and females (P value: 0.15 0.001).

According to sex, all the creatinine-based formulas showed significant differences while cystatin C-based formulas did not. This result was predictable due to the influence of sex factor in creatinine-based equations, while sex factor is not considered in cystatin C-based equations.

\subsection{To Summarize}

Our findings revealed that the abbreviated MDRD formula, among creatinine-based GFR formulas, provides GFRs closer to GFRs estimated by cystatin C-based equations in CKD patients. Since the cost of laboratory tests for cystatin $C$ is higher and it does not show superiority over MDRD, we recommend that the abbreviated MDRD formula be used for estimating GFR in CKD patients.

\subsection{Limitation}

There are two limitations for this study: 1 ) lack of a gold standard test and, 2) the small number of patients in the study.

\section{Footnotes}

Conflict of Interests: None declared. 
Funding/Support: This study was supported by the Research Foundation of Zanjan University of Medical Sciences, Zanjan, Iran.

\section{References}

1. Rose BD. Clinical physiology of acid-base and electrolyte disorders. McGraw-Hill; 1977.

2. Brochner-Mortensen J, Giese J, Rossing N. Renal inulin clearance versus total plasma clearance of 51Cr-EDTA. Scand J Clin Lab Invest. 1969;23(4):301-5. doi: 10.3109/00365516909081695. [PubMed: 4986443].

3. Aurell M. Accurate and feasible measurements of GFR-is the iohexol clearance the answer?.Nephrol Dial Transplant. 1994;9(9):1222-4. [PubMed: 7816278].

4. Star R, Hostetter T, Hortin GL. New markers for kidney disease. Clin Chem. 2002;48(9):1375-6. [PubMed: 12194910].

5. Levey AS, Coresh J, Balk E, Kausz AT, Levin A, Steffes MW, et al. National Kidney Foundation practice guidelines for chronic kidney disease: evaluation, classification, and stratification. Ann Intern Med. 2003;139(2):137-47. doi: 10.7326/0003-4819-139-2-20030715000013. [PubMed: 12859163].

6. Sjostrom PA, Odlind BG, Wolgast M. Extensive tubular secretion and reabsorption of creatinine in humans. Scand J Urol Nephrol. 1988;22(2):129-31. doi: 10.1080/00365599.1988.11690398. [PubMed: 3206217].

7. Sandilands EA, Dhaun N, Dear JW, Webb DJ. Measurement of renal function in patients with chronic kidney disease. Br J Clin Pharmacol. 2013;76(4):504-15. doi: 10.1111/bcp.12198. [PubMed: 23802624].

8. Maillard N, Mariat C, Bonneau C, Mehdi M, Thibaudin L, Laporte S, et al. Cystatin C-based equations in renal transplantation: moving toward a better glomerular filtration rate prediction?. Transplantation. 2008;85(12):1855-8. doi: 10.1097/TP.0b013e3181744225. [PubMed: 18580481].

9. Poge U, Gerhardt T, Stoffel-Wagner B, Palmedo H, Klehr HU, Sauerbruch T, et al. Prediction of glomerular filtration rate in renal transplant recipients: cystatin $\mathrm{C}$ or modification of diet in renal disease equation?. Clin Transplant. 2006;20(2):200-5. doi: 10.1111/j.13990012.2005.00466.x. [PubMed: 16640527].

10. Stevens LA, Coresh J, Greene T, Levey AS. Assessing kidney functionmeasured and estimated glomerular filtration rate. $N$ Engl $J$ Med. 2006;354(23):2473-83. doi: 10.1056/NEJMra054415. [PubMed: 16760447].

11. Oddoze C, Morange S, Portugal H, Berland Y, Dussol B. Cystatin C is not more sensitive than creatinine for detecting early renal impairment in patients with diabetes. Am J Kidney Dis. 2001;38(2):310-6. doi: 10.1053/ajkd.2001.26096. [PubMed: 11479157].

12. Le Bricon T, Thervet E, Froissart M, Benlakehal M, Bousquet B, Legendre C, et al. Plasma cystatin C is superior to 24 -h creatinine clearance and plasma creatinine for estimation of glomerular filtration rate 3 months after kidney transplantation. Clin Chem. 2000;46(8 Pt1):12067. [PubMed: 10926911].

13. Filler G, Lepage $\mathrm{N}$. Should the Schwartz formula for estimation of GFR be replaced by cystatin C formula?. Pediatr Nephrol. 2003;18(10):981-5. doi: 10.1007/s00467-003-1271-5. [PubMed: 12920638].

14. Hoek FJ, Kemperman FA, Krediet RT. A comparison between cystatin C, plasma creatinine and the Cockcroft and Gault formula for the estimation of glomerular filtration rate. Nephrol Dial Transplant. 2003;18(10):2024-31. doi: 10.1093/ndt/gfg349. [PubMed: 13679476].

15. Larsson A, Malm J, Grubb A, Hansson LO. Calculation of glomerular filtration rate expressed in $\mathrm{mL} / \mathrm{min}$ from plasma cystatin $\mathrm{C}$ values in $\mathrm{mg} / \mathrm{L}$. Scand J Clin Lab Invest. 2004;64(1):25-30. doi: 10.1080/00365510410003723. [PubMed: 15025426].

16. Rule AD, Bergstralh EJ, Slezak JM, Bergert J, Larson TS. Glomerular filtration rate estimated by cystatin $\mathrm{C}$ among different clinical pre- sentations. Kidney Int. 2006;69(2):399-405. doi:10.1038/sj.ki.5000073. [PubMed: 16408133].

17. Fried LF, Lee JS, Shlipak M, Chertow GM, Green C, Ding J, et al. Chronic kidney disease and functional limitation in older people: health, aging and body composition study. J Am Geriatr Soc. 2006;54(5):750-6. doi: 10.1111/j.1532-5415.2006.00727.x. [PubMed: 16696739].

18. Muntner P, Winston J, Uribarri J, Mann D, Fox CS. Overweight, obesity, and elevated serum cystatin C levels in adults in the United States. Am JMed. 2008;121(4):341-8. doi:10.1016/j.amjmed.2008.01.003. [PubMed: 18374694].

19. Stevens L, Greene T, Li C. Factors other than GFR influencing serum cystatin. JAm Soc Nephrol. 2007;18:547-8.

20. Kratchmarova I, Kalume DE, Blagoev B, Scherer PE, Podtelejnikov AV, Molina $\mathrm{H}$, et al. A proteomic approach for identification of secreted proteins during the differentiation of 3T3-L1 preadipocytes to adipocytes. Mol Cell Proteomics. 2002;1(3):213-22. doi: 10.1074/mcp.M200006-MCP200. [PubMed: 12096121].

21. Kopple JD. National kidney foundation $\mathrm{K} / \mathrm{DOQI}$ clinical practice guidelines for nutrition in chronic renal failure. Am J Kidney Dis. 2001;37(1 Suppl 2):S66-70. doi: 10.1053/ajkd.2001.20748. [PubMed: 11158865].

22. Grubb A. Non-invasive estimation of glomerular filtration rate (GFR). The Lund model: Simultaneous use of cystatin C- and creatinine-based GFR-prediction equations, clinical data and an internal quality check. Scand J Clin Lab Invest. 2010;70(2):65-70. doi: 10.3109/00365511003642535. [PubMed: 20170415].

23. Baxmann AC, Ahmed MS, Marques NC, Menon VB, Pereira AB, Kirsztajn $\mathrm{GM}$, et al. Influence of muscle mass and physical activity on serum and urinary creatinine and serum cystatin C. Clin J Am Soc Nephrol. 2008;3(2):348-54. doi: 10.2215/CJN.02870707. [PubMed: 18235143].

24. Tangri N, Stevens LA, Schmid CH, Zhang YL, Beck GJ, Greene T, et al. Changes in dietary protein intake has no effect on serum cystatin $C$ levels independent of the glomerular filtration rate. Kidney Int. 2011;79(4):471-7. doi: 10.1038/ki.2010.431. [PubMed: 20980977].

25. Dharnidharka VR, Kwon C, Stevens G. Serum cystatin C is superior to serum creatinine as a marker of kidney function: a meta-analysis. $\mathrm{Am}$ J Kidney Dis. 2002;40(2):221-6. doi: 10.1053/ajkd.2002.34487. [PubMed: 12148093].

26. Grubb A, Bjork J, Lindstrom V, Sterner G, Bondesson P, Nyman U. A cystatin C-based formula without anthropometric variables estimates glomerular filtration rate better than creatinine clearance using the Cockcroft-Gault formula. Scand J Clin Lab Invest. 2005;65(2):153-62. doi: 10.1080/00365510510013596. [PubMed: 16025838].

27. Perkins BA, Nelson RG, Krolewski AS. Cystatin C and the risk of death. N Engl J Med. 2005;353(8):842-4. doi: 10.1056/NEJMc051667. [PubMed: 16124125] author reply 842-4.

28. Gokkusu CA, Ozden TA, Gul H, Yildiz A. Relationship between plasma Cystatin $\mathrm{C}$ and creatinine in chronic renal diseases and Tx-transplant patients. Clin Biochem. 2004;37(2):94-7. [PubMed: 14725938].

29. Thomassen SA, Johannesen IL, Erlandsen EJ, Abrahamsen J, Randers E. Serum cystatin C as a marker of the renal function in patients with spinal cord injury. Spinal Cord. 2002;40(10):524-8. doi: 10.1038/sj.sc.3101320. [PubMed: 12235535].

30. Jenkins MA, Brown DJ, Ierino FL, Ratnaike SI. Cystatin C for estimation of glomerular filtration rate in patients with spinal cord injury. Ann Clin Biochem. 2003;40(Pt 4):364-8. doi: 10.1258/000456303766476995. [PubMed: 12880536].

31. Beringer PM, Hidayat L, Heed A, Zheng L, Owens H, Benitez D, et al. GFR estimates using cystatin $C$ are superior to serum creatinine in adult patients with cystic fibrosis. J Cyst Fibros. 2009;8(1):19-25. doi: 10.1016/j.jff.2008.07.004. [PubMed: 18799365].

32. Momtaz HE, Dehghan A, Karimian M. Correlation of cystatin C and creatinine based estimates of renal function in children with hydronephrosis. J Renal Inj Prev. 2016;5(1):25-8. doi: 10.15171/jirip.2016.06. [PubMed: 27069964]. 
33. Stevens LA, Coresh J, Schmid CH, Feldman HI, Froissart M, Kusek J, et al. Estimating GFR using serum cystatin $\mathrm{C}$ alone and in combination with serum creatinine: a pooled analysis of 3,418 individuals with CKD. Am J Kidney Dis. 2008;51(3):395-406. doi: 10.1053/j.ajkd.2007.11.018. [PubMed: 18295055].

34. Cepeda FJ, Fernandez E, Pobes A, Banos LM. [Utility of cystatin-C in hospitalized patients. Comparing with different methods of assessing renal function]. Nefrologia. 2007;27(2):168-74. [PubMed: 17564561].

35. Donadio C, Lucchesi A, Ardini M, Giordani R. Cystatin C, beta 2microglobulin, and retinol-binding protein as indicators of glomerular filtration rate: comparison with plasma creatinine. J Pharm Biomed Anal. 2001;24(5-6):835-42. doi: 10.1016/S0731-7085(00)005501. [PubMed: 11248475 ]
36. Knight EL, Verhave JC, Spiegelman D, Hillege HL, de Zeeuw D, Curhan $\mathrm{GC}$, et al. Factors influencing serum cystatin $\mathrm{C}$ levels other than renal function and the impact on renal function measurement. Kidney Int. 2004;65(4):1416-21. doi: 10.1111/j.1523-1755.2004.00517.x. [PubMed: 15086483].

37. Wasen E, Isoaho R, Mattila K, Vahlberg T, Kivela SL, Irjala K. Serum cystatin $\mathrm{C}$ in the aged: relationships with health status. Am J Kidney Dis. 2003;42(1):36-43. doi: 10.1016/S0272-6386(03)00406-2. [PubMed: 12830454].

38. Uzun H, Ozmen Keles M, Ataman R, Aydin S, Kalender B, Uslu E, et al. Serum cystatin $C$ level as a potentially good marker for impaired kidney function. Clin Biochem. 2005;38(9):792-8. doi: 10.1016/j.clinbiochem.2005.05.012. [PubMed:16005452]. 